\title{
Pitting Corrosion of 2205 Duplex Stainless Steel at High Concentrations of $\mathrm{NaCl}$ Solution
}

\author{
Chuan Liu ${ }^{1,2}$, Min Gong ${ }^{1,2, *}$, Xingwen Zheng ${ }^{2,3}$ \\ ${ }^{1}$ School of Material and Science Engineering, Sichuan University of Science \& Engineering, Zigong \\ 643000, China, Zigong 643000, China \\ ${ }^{2}$ Key Laboratory of Material Corrosion and Protection of Sichuan Province, Zigong 643000, China \\ ${ }^{3}$ School of Chemical and Environmental Engineering, Sichuan University of Science \& Engineering, \\ Zigong 643000, China \\ *E-mail: gmsuse@ 126.com
}

doi: $10.20964 / 2018.08 .41$

Received: 8 February 2018 / Accepted: 22 May 2018 / Published: 5 July 2018

\begin{abstract}
Critical pitting temperature (CPT) of 2205 duplex stainless steel (2205 DSS) in different concentrations of $\mathrm{NaCl}$ solution was investigated through cyclic voltammetry and potentiostatic technique, and the difference of corrosion behavior of 2205 DSS in $\mathrm{NaCl}$ solution under high and low CPT was compared. The results revealed that the concentration of $\mathrm{NaCl}$ solution has little effect on CPT of 2205 DSS in the range of studied concentrations $(50 \sim 300 \mathrm{~g} / \mathrm{L})$, and the CPT is between 40 and $45{ }^{\circ} \mathrm{C}$. However, the corrosion current density, electrochemical impedance and corrosion morphology of 2205 DSS were significantly different under temperatures below the CPT and above the CPT.
\end{abstract}

Keywords: 2205 DSS ; NaCl solution; CPT; pitting corrosion

\section{FULL TEXT}

(C) 2018 The Authors. Published by ESG (www.electrochemsci.org). This article is an open access article distributed under the terms and conditions of the Creative Commons Attribution license (http://creativecommons.org/licenses/by/4.0/). 